\title{
A figura de retórica Quiasma aplicada à argumentação visual ${ }^{1}$
}

The Application of Chiasm to Visual Argumentation

Laene Mucci Daniel ${ }^{2}$

\begin{abstract}
RESUMO: Este trabalho visa relacionar a figura de retórica Quiasma ao princípio do design Contraste. Na percepção de que o contraste no quiasma acontece principalmente pelo cruzamento de lugar (e não de significado), concluímos que, ao posicionar dois elementos diferentes, o quiasma não apresenta uma oposição dicotômica que separa os elementos de forma cartesiana. É um contraste em que as palavras/ideias se posicionam em lados separados, mas num arranjo argumentativo orgânico, interdependentes, sem extremismos.
\end{abstract}

Palavras-chave: Quiasma; Retórica da imagem; Contraste. Comunicação visual.

ABSTRACT: Chiasm is a figure of speech which relates to the principle of contrast in design. Contrast in chiasm happens largely by the switching of place rather than the meaning, leading to the conclusion that the positioning of two distinct elements does not constitute a dichotomous opposition that separates the elements in a Cartesian fashion. The contrast lies in how the words or ideas position themselves side by side in an organic argument, which is neither interdependent nor extreme.

Keywords: Chiasm; Rhetoric of the image; Contrast; Visual communication.

\section{Introdução}

Ao tratar da Retórica prática, em aula ministrada em 18 de março de 2014, pela disciplina “A Retórica: de suas origens aos dias atuais", na Faculdade de Letras da Universidade Federal de Minas Gerais, a professora Tereza Virgínia Ribeiro Barbosa defendeu que o "discurso retórico precisa ser visual", apresentando-nos a quiasma, uma "figura de pensamento literária de linguagem", possuidora de uma "estrutura de convencimento, contra-argumentativa sofisticada" (BARBOSA, 2014). Num primeiro momento, o exemplo apresentado ("aqueles que semeiam chorando colhem cantando"), nos remeteu ao conceito de contraste, um dos

\footnotetext{
${ }^{1}$ Trabalho produzido na disciplina "A Retórica: de suas origens aos dias atuais", do programa de Pós-graduação em Estudos Linguísticos, Faculdade de Letras, Universidade Federal de Minas Gerais, UFMG.

${ }^{2}$ Doutoranda em Estudos Linguísticos na Faculdade de Letras da Universidade Federal de Minas Gerais, UFMG. laenemucci@gmail.com
} 
princípios do design, segundo Robin Williams (1995) na sua obra que trata das noções básicas de planejamento visual. A figura Quiasma - também denominada quiasmo - é representada pela letra grega "Qui" forma um " $\mathrm{X}$ " em que as palavras se posicionam de forma oposta, conforme Figura 1.

Figura 1: Representação visual de Quiasma

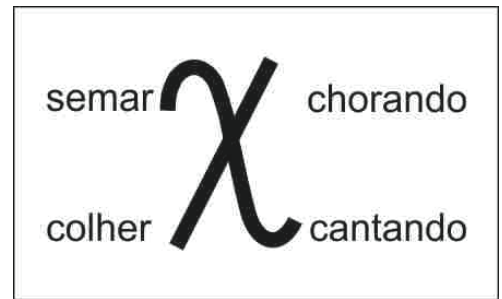

Fonte: Baseado em BARBOSA (2014)

Entendemos, inicialmente, que a quiasma é uma construção de palavras e ideias contrastantes que auxiliam na compreensão e no destaque da mensagem. Frases construídas em forma de quiasma impactam. Da mesma forma, o princípio do contraste objetiva "criar interesse sobre uma página; se ela tiver uma aparência interessante, atrairá leitura" (WILLIAMS, 1995, p. 62). Ambos, quiasma e contraste, são formas de valor argumentativo para despertar o interesse e ajudar na adesão à mensagem apresentada.

Para discutir a relação percebida entre a figura quiasma e o princípio contraste, iniciamos um estudo entre retórica e comunicação e retórica e imagem. Ao nos aprofundarmos na relação entre a figura e o princípio (PERELMAN; OLBRECHTS-TYTECA, 2005; ARISTÓTELES, 2005; WILLIAMS, 1995; COIMBRA, 2007), percebemos que a afinidade não é de conteúdo, como inicialmente acreditamos, mas de posição.

\section{A Retórica e a Comunicação}

No tratado da argumentação, Perelman e Olbrechts-Tyteca (2005), em consonância com Aristóteles (2005), reafirmaram o caráter utilitário da retórica, reconhecendo seu papel em sistematizar as relações comunicacionais entre os humanos. Em outro estudo, Perelman relaciona a comunicação à retórica: 
Desde que uma comunicação tenda a influenciar uma ou várias pessoas, a orientar o seu pensamento, a exercitar ou a apaziguar as emoções, a dirigir uma ação, ela é do domínio da retórica. (PERELMAN, 1997, p.177 apud PINHEIRO, 2012, p. 49).

Ainda em acordo com Pinheiro (2012), acreditamos que jornais e reportagens, bem como anúncios publicitários, sob o efeito da retórica (a arte do discurso), tornam-se discursos contemporâneos. Entendemos esse efeito como um ato retórico

[...] que cria uma mensagem, cujo teor e forma, começo e fim são nela marcados por um autor humano, com um propósito, para uma audiência (CAMPBELL, 1982 apud PINHEIRO, 2012, p. 25).

Enquanto a retórica clássica focava a expressão oral e performática do orador, atualmente o verbal e o visual, nos meios de comunicação, são fundamentais para argumentar (PINHEIRO, 2002, p. 80).

Se o ato retórico, portanto, é "uma tentativa intencional (...) com uma audiência específica (...) para conseguir um determinado objetivo" (CAMPBELL, 1982 apud PINHEIRO, 2012, p. 25), compreendemos o ato de planejar visualmente um anúncio ou uma reportagem como um ato retórico em que, assim como defendeu Aristóteles (2005), escolhe os meios apropriados para persuadir. Mesmo que os estudos de retórica da imagem empreendidos por Roland Barthes (1990), Umberto Eco, Jacques Durand, Georges Péninou, Jean Marie Floch (apud SANTARELLI; SOUZA, 2006), Martine Joly (1996), Jacques Aumont (2004), tenham se dado sob um corpus de anúncios publicitários, vislumbramos nosso estudo a partir de qualquer suporte que necessite de um planejamento visual, seja ele um anúncio publicitário ou uma matéria jornalística, ambos apresentando, para além da mensagem textual, a mensagem visual, porque compreendemos que a retórica da imagem inclui

[...] un conjunto de operaciones artificiosas que caracterizan el mensaje y buscan el asentamiento persuasivo y emotivo por parte de los receptores. (FONT, 1981, p. 18 apud DIAZ, 2005, p. 7).

É nesse sentido que os textos jornalísticos iconográficos, ou seja, suas mensagens visuais compartilham finalidades com as imagens publicitárias (DÍAZ, 2005). São as finalidades de chamar a atenção, persuadir, se tornar compreensíveis, porque não basta somente o discurso enquanto conteúdo, mas também o discurso como forma em que se apresenta. 
Segundo Aristóteles, “[...] não basta possuir a matéria do discurso; urge necessariamente exprimir-se na forma conveniente, o que é de suma importância para dar ao discurso uma aparência satisfatória" (ARISTÓTELES, 2005, p. 173).

Acreditamos, portanto, que "a comunicação é intrínseca à retórica, pois, ao comunicar algo, pretende-se compartilhar uma ideia e, ao ter o convencimento como objetivo, a argumentação é um dos fatores primordiais para a eficiência desse discurso persuasivo" (PINHEIRO, 2012, p. 49).

\section{A Retórica e as Figuras}

As figuras de retórica, apesar das críticas, desde Aristóteles, não são consideradas, somente como ornamentos. No século XIX, o estudo taxionômico de Fontanier concentrava-se sobre a dimensão persuasiva das figuras (BONHOMME, 2009). Assim como a própria retórica, elas foram renovadas, a partir do Tratado de Perelman e Olbrechts-Tyteca, e deixaram de ser vistas como ornamentais para incorporarem um caráter mais argumentativo (PINHEIRO, 2012, p. 64). A figura é “[...] uma fruição a mais, uma licença estilística para facilitar a aceitação do argumento" (REBOUL, 2004, p. 114). Para Reboul, a figura é considerada de retórica quando desempenha um papel persuasivo. Figura de retórica, para o autor, é qualquer tipo de recurso ou manipulação da linguagem com fins persuasivos, expressivos ou estéticos com o objetivo de ampliar o significado ou a ênfase que o orador quer imprimir em seu discurso (REBOUL, 2004).

Em seu trabalho sobre a relação entre a função argumentativa e a estilística das figuras de retórica, Marc Bonhomme (2009) discorda de Perelman, que valoriza a dimensão argumentativa das figuras com relação à dimensão estilística. Para Bonhomme, "[...] toute ces fonctions figurales ont en príncipe la même valeur, chacune d'entre elles étant pertinente selon la situation de comunication òu elle se manifeste (2009, p. 5). Essas funções não são decididas, a priori, elas decorrem da produção dos discursos. Nosso estudo, portanto, compreende que as figuras de linguagem são importantes ao discurso, pela sua função, tanto argumentativa quanto estética.

Em sua análise discursiva acerca da comunicação, Alice Krieg-Planque relembra que as figuras de discurso são mecanismos conhecidos da retórica, importantes e "inseparáveis" para o momento que a retórica clássica chama de memória, "cujo interesse consiste no que é feito, 
no discurso, para ele ser memorizado e eventualmente retomado" (KRIEG-PLANQUE, 2011, p. 3).

Foi Fontanier que, em 1818, traçou a taxionomia mais rica e sistemática das figuras de retórica, dividindo uma centena delas em classes repartidas em gêneros, espécies e variedades (CHARAUDEAU; MAINGUENEAU, 2004). Estudos mais recentes têm proposto outras tipologias. Olivier Reboul (2004) classificou e nomeou as figuras de retórica de acordo com a forma que se relacionam ao discurso no qual são encaixadas: figuras de palavras (o fônico), de sentido (o sintático) e de construção (o semântico) e de pensamento.

As figuras de palavras referem-se à sonoridade; as de sentido alteram o significado das palavras; as de pensamento tratam da relação do discurso e o sujeito (orador); as de construção são aquelas nas quais se situa a quiasma, referem-se à ordem natural das palavras ou do discurso e seus procedimentos são por subtração, repetição ou permutação (REBOUL, 2004).

Também chamadas de metataxes, as figuras de construção resultam de manobras ocorridas "na expressão e na forma plástica dos enunciados. Operam efetivamente na relação sintática dos vocábulos, mas seu efeito incide tanto na expressão como no conteúdo" (HUBERT, 2011, p. 50).

Tanto Aristóteles (2005) quanto Reboul (2004) e Barthes (2001 apud Pinheiro, 2012), em suas classificações sistêmicas da retórica, citaram a operação Elocutio (elocução) como o momento que não diz respeito à palavra oral, mas ao estilo, quando são acrescentadas as figuras retóricas. Para Martha C. Chamorro Díaz, "[...] dentro de la elocutio se encuentra el ornatus, o la forma de embelecer el texto, y dentro de éste, las figuras retóricas” (DÍAZ, 2005, p. 5).

$\mathrm{Na}$ elocução, ao se constituir o estilo do discurso e das suas figuras, presencia-se uma carga imagética, tanto em termos heurísticos quanto da própria produção de imagens, de modo que algumas figuras de estilo são consideradas e conceituadas como imagens (FERREIRA et $a l, 2008)$.

Las figuras retóricas (consciente o inconscientemente) son las que permiten la interrelación de todos los signos que componen el espacio de la imagen. Esta última permite que la imagen logre los supuestos mundos, probables o improbables que describe. (DÍAZ, 2005, p. 7).

\section{A Retórica e a Imagem}

Olivier Reboul afirmou que "a imagem é retórica a serviço do discurso, não em seu lugar" (REBOUL, 2004, p. 85). Roland Barthes, o precursor dos estudos da retórica da imagem, 
discordou de Reboul, retrucando que tudo é imagem, seguido por Maria Augusta Babo: "toda a expressão remete para um conteúdo de dimensão imagética" (BABO, 2005, p. 110 apud PINHEIRO, 2012, p. 82).

Segundo Lineide Mosca (2004), a ciência da retórica é necessária ao nosso mundo contemporâneo, no qual o poder é instituído pelo simbólico: palavras e imagens. "O nosso universo está repleto de imagens. $\mathrm{O}$ nosso pensar passa pelas imagens. $\mathrm{O}$ nosso sentir não as ignora. O nosso agir habituou-se a lidar com elas (ABRANTES, 1999, p. 2).

Como afirmam Santarelli e Souza (2006), Roland Barthes defendeu a existência de uma retórica da imagem semelhante à retórica verbal. Com o trabalho Retórica da imagem, de 1964, Barthes abriu caminhos para futuros estudos sobre a imagem.

A partir da premissa de Barthes, demonstrando que os conceitos da retórica tradicional poderiam ser aplicados à imagem publicitária, Durand, em um corpus de mais de mil anúncios publicados nos anos de 1960, constituiu uma retórica visual, traduzindo todas as figuras da retórica clássica verbal em imagens (SANTARELLI; SOUZA, 2006).

Para identificar as figuras da retórica visual, Durand iniciou seu estudo construindo uma tabela de relações entre os conteúdos e as formas das figuras de retórica, estabelecendo, no plano do conteúdo, cinco tipos possíveis de relações entre os elementos associados (...) e, no plano das formas, quatro tipos de operações retóricas. (DURAND apud SANTARELLI; SOUZA, 2006, p. 7-8).

No plano do conteúdo, foram relacionados cinco tipos de relações entre os elementos associados: identidade, similaridade, diferença, oposição e falsa homologia. No plano da forma, estabeleceram-se quatro tipos de operações retóricas: adjunção, supressão, substituição e troca. Nessa classificação geral das figuras de retórica, a figura quiasma foi classificada quanto ao seu conteúdo como oposição e quanto à sua forma como operação de troca (SANTARELLI; SOUZA, 2007, p. 8).

\section{A Figura de Retórica: Quiasma}

A palavra quiasma vem do vocábulo grego khiasmós que determina uma disposição de duas letras cruzadas, tal como a letra grega $k h i$, representada visualmente sob a forma de $X$, conforme mostrado na Figura 1. "Como um recurso gramatical e retórico, a figura do quiasma define-se basicamente como um paralelismo invertido, ou seja, a distribuição dos elementos 
não é correlativa, mas sim cruzada" (COIMBRA, 2007, p. 1) Na sua superfície textual, a figura quiasma opera sobre a estrutura frásica, dispondo quatro elementos, dois a dois, numa estrutura cruzada, do tipo AB-BA. Como na máxima de Quintiliano, Non ut edam vivo, sed vivam edo, que se traduz em "Não vivo para comer, mas como para viver", em que fica clara a inversão dos pares de construções simétricas (COIMBRA, 2007). Ou no trecho bíblico "os últimos serão os primeiros, e os primeiros serão os últimos" (MATEUS, 20, 16).

Ao tratar de recursos estilísticos, Ribeiro explica que "o quiasmo aparece quando duas partes de frase ou frases completas, que contêm uma anáfora ${ }^{3}$, não são construídas paralelamente, mas em oposição, como imagem e reflexo" (RIBEIRO, s/d), conforme demonstrado na Figura 2. Hubert informa que a figura quiasma, também chamada de conversão, é obtida quando uma ordem simétrica é desenvolvida de forma contrária, "em que há uma simetria em cruz, que pode valer tanto para o sentido como para a gramática" (HUBERT, 2011, p. 55).

Figura 2: A estrutura cruzada do quiasma

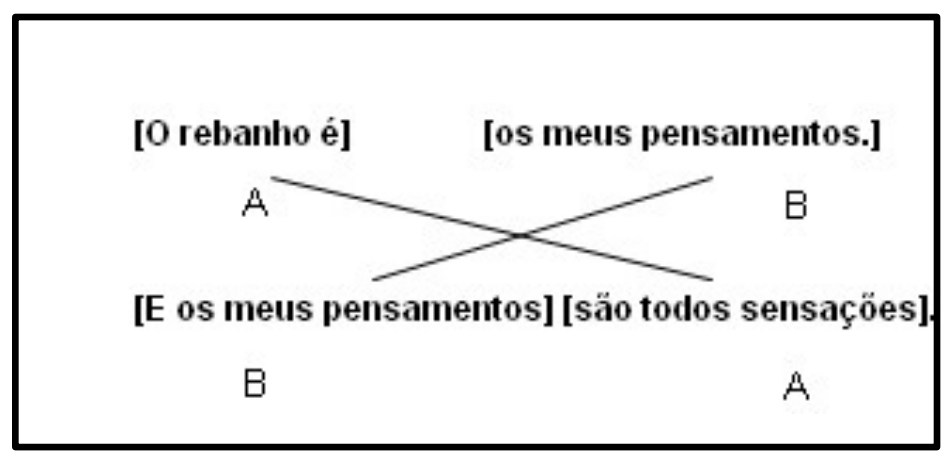

Fonte: http://www.infopedia.pt/\$quiasmo;jsessionid=fJOM7bEh3H37NcbmOChb6w

Para Wiseman (2001 apud Coimbra, 2007), o quiasmo pode ser abordado do ponto de vista da organização do pensamento e "a sua função tem sido comparada com a de outras contraposições conceptuais: as dicotomias e os pares dialécticos, por um lado, e as simples oposições de conceitos e as oposições complementares, por outro" (GONZÁLEZ, 1995 apud COIMBRA, 2007).

Ao permutar simetricamente termos de uma frase ou expressão, o quiasma "geralmente é empregado para contrastar significados", exemplificado em "Veja não tira os olhos do Brasil.

\footnotetext{
${ }^{3}$ Em retórica, anáfora é a repetição da mesma palavra ou grupo de palavras no princípio de frases ou versos consecutivos.
} 
E o Brasil não tira os olhos de Veja" (GONZÁLES, 2003, p. 129). A partir do cruzamento mostrado na Figura 2, fica claro, entretanto, que a oposição não se apresenta exclusivamente entre significados dicotômicos. O que contrasta no quiasma é a disposição cruzada de frases, palavras ou trechos de frases que chamam a atenção pelas posições opostas que ocupam, na forma de $X$. O contraste no quiasma pode ser pela posição cruzada de conceitos, significados ou ideias também opostos entre si, conforme os seguintes exemplos:
a) Era fera lá fora, em casa carneiro era.
b) Quem semeia devagar, depressa colhe.
c) Morro porque te odeio. Amo-te porque vivo.

Mas pode acontecer também pela simples inversão de posições que ocupam os elementos da construção frasal, vista nos exemplos:

a) A bênção como espada. A espada como benção.

b) Vinhas fatigada e triste, e triste e fatigada eu vinha.

c) Vende mais porque é mais fresquinho. É mais fresquinho por que vende mais?

Não nos interessa aqui aprofundar na configuração linguística do quiasmo, bem desenvolvida em Coimbra (2007). Basta-nos constatar que, pequeno ou grande, construído com duas ou quatro frases, simples ou composto, semântico ou sintático, o quiasma é um tipo de paralelismo que se distingue pela posição cruzada dos elementos coordenados que frequentemente "expresan unos conceptos antitéticos ${ }^{4}$. Los elementos cruzados pueden ser idênticos o distintos" (SPANG, 1991, p. 147 apud COIMBRA, 2007, p. 3). Semelhantes ou diferentes, os elementos do quiasma diferenciam-se e chamam a atenção porque contrastam, de forma cruzada. O quiasma é, portanto, uma figura de construção de contrastes.

6 O Princípio do Design: Contraste

Segundo Williams, o contraste "costuma ser a mais importante atração visual de uma página" (1995, p. 14). Além de auxiliar na "organização das informações”, ele seduz o olhar e ajuda na leitura.

\footnotetext{
${ }^{4}$ Aquilo que pode ser relacionado ao oposto, sentido de contrário, ambiguidade.
} 
O leitor deveria ser capaz de compreender instantaneamente a maneira através da qual as informações são estruturadas, o fluxo lógico de um item para outro. Os elementos contrastantes nunca deveriam confundir o leitor ou criar um foco que não seja o correto. (WILLIAMS, 1995, p. 62).

O contraste tem como propósito básico criar interesse sobre uma página. Para isso, é preciso posicionar dois elementos diferentes, eles "não devem ser similares". O interesse visual só é criado se os itens contrastarem entre si, com elementos marcantes. "Se os itens não forem exatamente iguais, diferencie-os!" (WILLIAMS, 1995, p. 62). Williams afirma que a maneira mais fácil de acrescentar contraste é trabalhar com as fontes (conceito da área da Editoração para tipo de letra). Uma fonte bold (negrito) com outra light (fina), por exemplo. Ou contrastando palavras da mesma fonte em letras maiúsculas com outras em minúsculas, letras grandes com letras pequenas, fontes em estilo antigo com outras modernas (conforme Figura 3). Para Williams, a combinação de fontes diferentes deve aperfeiçoar a comunicação e não confundir.

Figura 3: Contraste de estilos de fontes

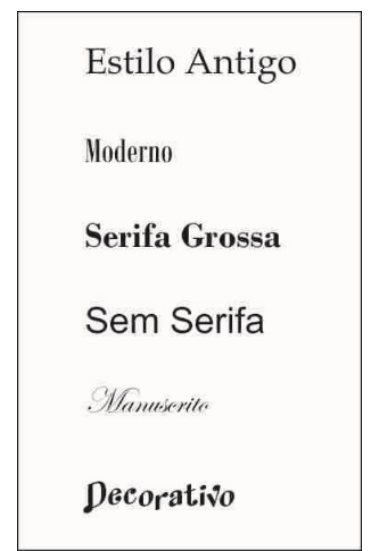

Fonte: adaptado de Williams, 1995, p. 83

O autor afirma que a tipologia é uma das maneiras mais eficazes de se conferir contrastes, mas ensina outras maneiras de contrastar os itens:

[...] uma cor fria com uma mais quente; uma textura áspera com uma lisa; um elemento horizontal (por exemplo, uma longa linha de texto) com um elemento vertical (por exemplo, uma coluna estreita de texto); linhas muito espaçadas com linhas bem próximas; uma figura pequena com uma figura grande. (WILLIAMS,1995, p. 53). 
A partir dessa afirmação, Mucci Daniel (2014) percebe a existência de outros contrastes tão marcantes quanto o tipológico e propõe uma classificação mais abrangente. Enquanto Williams (1995, p. 82) afirma a existência de "seis maneiras claras e diferentes de contrastar a tipologia: tamanho, peso, estrutura, forma, direção e cor", a professora classifica o contraste em seis grandes tipos: cor, posição, espessura, tamanho, aparência e representação de ideias/conceitos, entendendo que eles atendem a vários recursos visuais: fonte, foto, ilustração, fio, box, infográfico. A fonte, assim como outros recursos visuais, pode ser aplicada de forma contrastante em relação à sua cor, posição, espessura, tamanho, aparência e até em representação de ideias/conceitos, no caso das fontes decorativas (ver Figura 4).

Figura 4: Contraste de representação de ideias em fontes

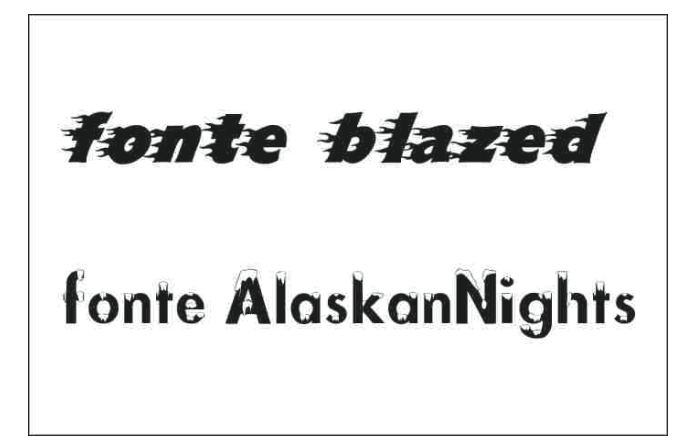

Fonte: http://www.netfontes.com.br/fontes.php/categ_0.10.htm

Segundo Mucci Daniel (2014), os seis grandes tipos ainda aceitam um número ilimitado de subdivisões contrastantes, de acordo com as observações e descobertas dos pesquisadores. De imediato, a pesquisadora subdividiu os seis grupos em:

a) cor (claro e escuro, nítido e embaçado, suave e forte);

b) posição (em cima e embaixo, à direita e à esquerda, vertical e horizontal, atrás e à frente)

c) espessura (fino e grosso);

d) tamanho (pequeno e grande);

e) aparência (vestido e nu, cabeludo e careca, novo e velho, gordo e magro, quente e frio, leve e pesado, redondo e quadrado);

f) representação de ideias/conceitos (mau e bom, anjo e diabo, rural e urbano, pobre e rico, direita e esquerda políticas, alegria e tristeza). 
O contraste de cor acontece quando as cores realmente se diferenciam. Preto e cinza não contrastam, a não ser que o cinza seja claro, pelo menos $50 \%$ do preto total. As cores podem se diferenciar em claro e escuro, azul celeste e azul marinho; suave e forte, vermelho e verde água; nítido e embaçado, formas focadas e desfocadas, por exemplo. A Figura 5 mostra a capa da revista Vida Simples, edição 92 de maio de 2010, em que há o contraste do azul e laranja, do branco e laranja, do branco e azul.

Figura 5: Contraste de cor

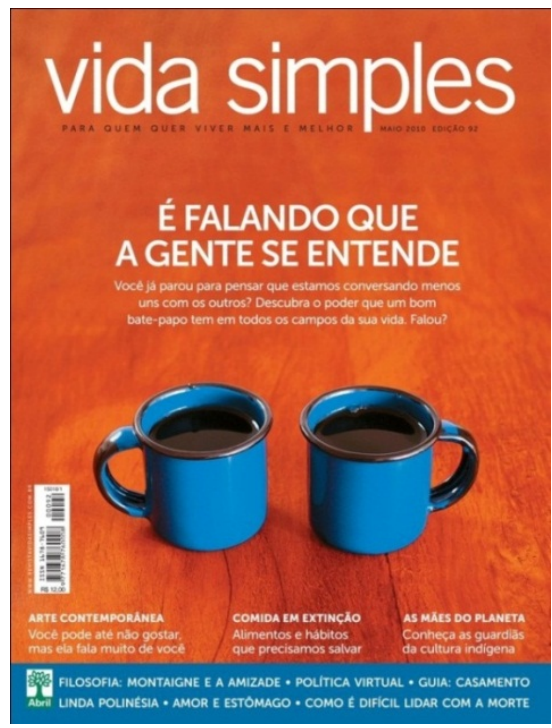

Fonte: http://lepetitvert.blogspot.com.br/p/festas-tematicas.html

O contraste de posição abrange muitas possibilidades (em cima e embaixo, à direita e à esquerda, vertical e horizontal, atrás e à frente), conforme visto na Figura 6, em que a página do caderno Pensar do jornal Estado de Minas, de 11/08/2012, traz duas fotos posicionadas em cima à direita e embaixo à esquerda contrastando entre si.

Os contrastes de espessura e tamanho são muito usados entre fontes bold (negrito) e light (fina); fios (linhas verticais ou horizontais que separam as matérias nas páginas de jornal) de milímetros desiguais; fontes, fotos e, ou pessoas pequenas e grandes, conforme apresenta a Figura 7. 
Figura 6: Contraste de posição

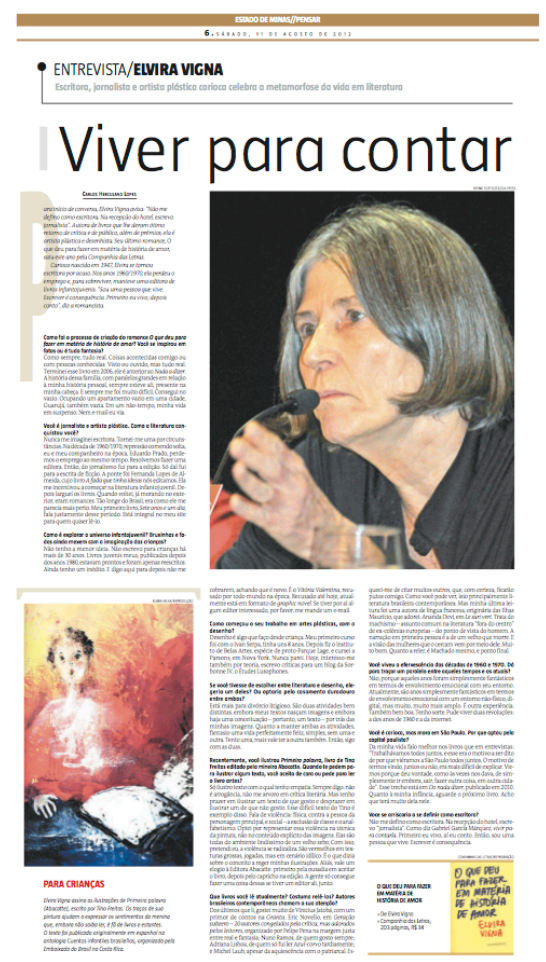

Fonte: http://iteratino.blogspot.com.br/2012/08/elvira-vigna-em-entrevista-ao-estado-de.html

A capa do jornal Folha de São Paulo, de 28/0302014, traz duas fotos contrastando em tamanho: a que se refere à manifestação popular contra o evento da Copa do Mundo é maior do que a do encontro entre o papa e o presidente dos EUA. O título "Decisão do Supremo atrasará processo do mensalão tucano" é apresentado com destaque, em fontes "mais espessas" (negrito ou bold) em corpo de letra maior do que os outros títulos da capa.

Os contrastes de aparência e de ideias/conceitos são muito usados em mensagens publicitárias, campanhas políticas, ensaios fotográficos. A Figura 8 apresenta uma peça gráfica da campanha publicitária veiculada pela cerveja Devassa, em 2011. A campanha teve o seu conceito (ou tema) principal criado a partir de um contraste de ideias que repercutiu publicamente, provocando comentários variados, gerando mídia gratuita para a cervejaria. Ao veicular peças gráficas e eletrônicas (anúncio, outdoor, comerciais de TV) contrastando o nome/significado Devassa com a garota propaganda Sandy, uma cantora que sempre foi associada aos conceitos de mocinha comportada, pura, nada transgressora e muito menos devassa, a empresa alcançou seu objetivo, chamando bastante a atenção e ajudando a persuadir seu público-alvo (as mulheres tomadoras de cerveja), pela mensagem implícita: toda mulher tem seu lado devassa. 
Figura 7: Contrastes de espessura e tamanho

\section{FOLHA DE S.PAULO}

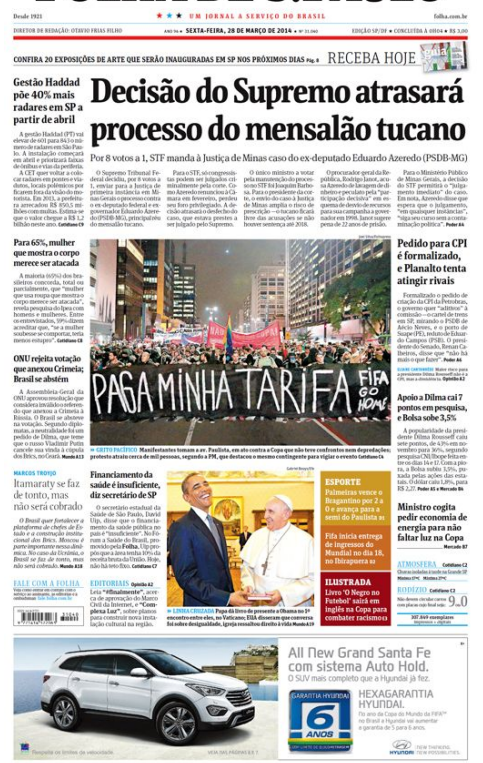

Fonte: http://www1.folha.uol.com.br/fsp/cp28032014.shtml

Figura 8: Contraste de ideias/conceitos

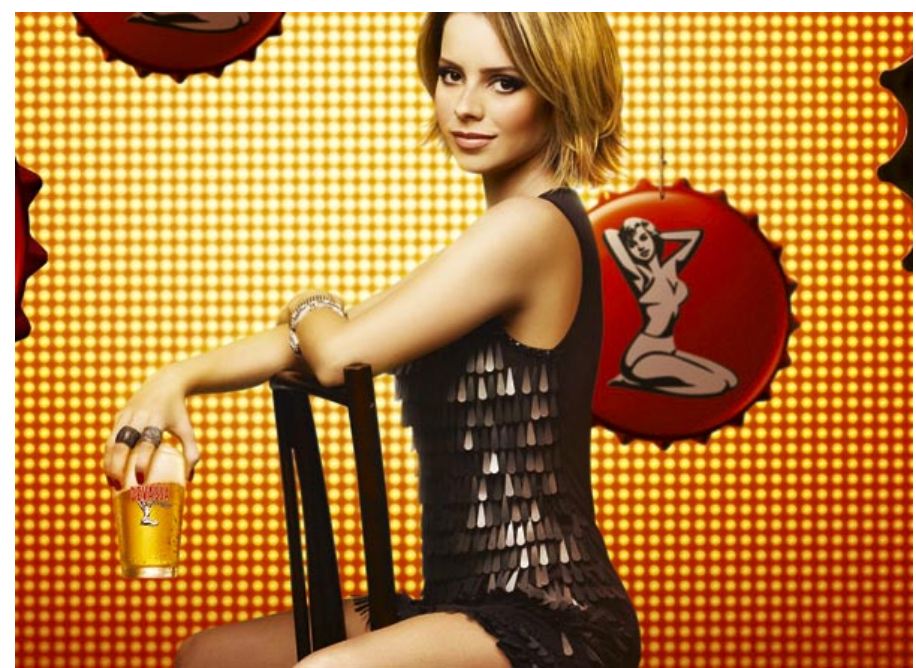

Fonte: http://mingauideias.blogspot.com.br/2012/05/mercado-vinculando-artista-marcas.html

Esse tipo de contraste, muito convincente, é o mesmo usado na campanha da empresa italiana Benetton, nas décadas de 1980 e $1990^{5}$, quando as imagens da freira beijando um padre,

\footnotetext{
${ }^{5}$ Campanhas "Militants Contrasts: black and White" (1989/1990); “Angel and Devil” (1991/1992), entre outras.
} 
crianças branca e negra se abraçando, líderes palestino e muçulmano apertando as mãos chamaram a atenção de todo o mundo pelos seus contrastes de ideias/conceitos.

O jornalismo também conhece a eficácia desse tipo de contraste. Fator de impacto na fotojornalismo, o contraste de conceitos pode ser vislumbrado nas Figuras 9 a 11.

Figura 9: Banhistas e religiosos contrastam na praia, 2013

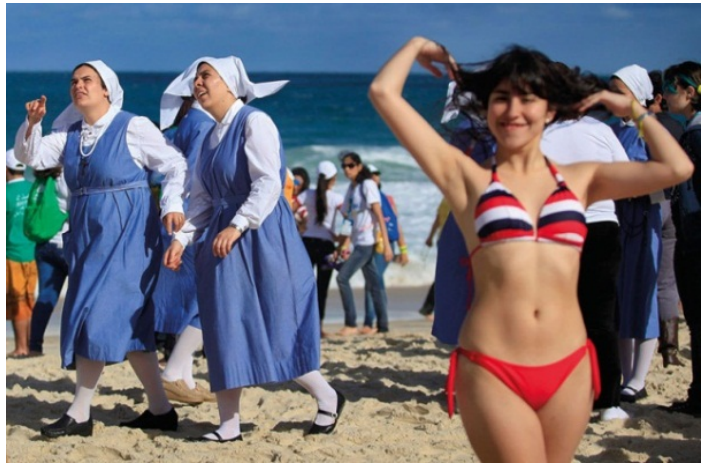

Fonte: http://photos.uol.com.br/materias/ver/96281. Fotógrafo Ricardo Moraes
Figura 10: O contraste entre casais rebeldes em manifestação no Rio de Janeiro, 2014

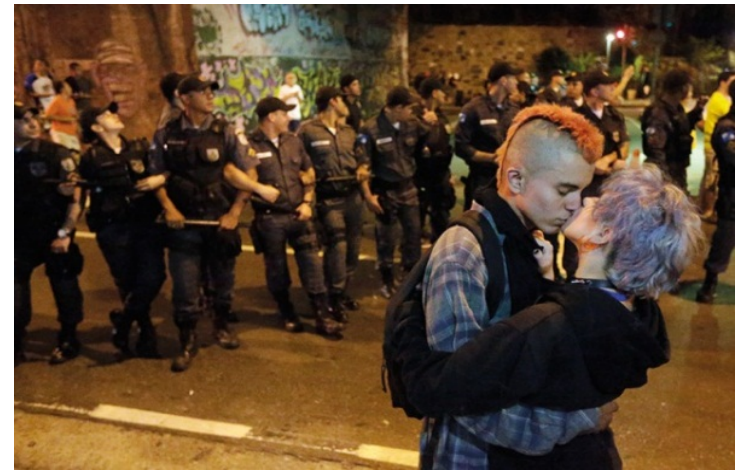

Fonte: http://photos.uol.com.br/materias/ver/96281. Fotógrafo Ricardo Moraes

Tanto na Figura 9 quanto na Figura 10, para além da aparência, o corpo descoberto contrastando com o todo coberto; o corpo em sentido contrastando com o corpo entregue ao beijo, o contraste marcante é o de comportamento que representa visões de mundo, ideias diferentes.

Figura 11: O contraste entre a ficção e realidade

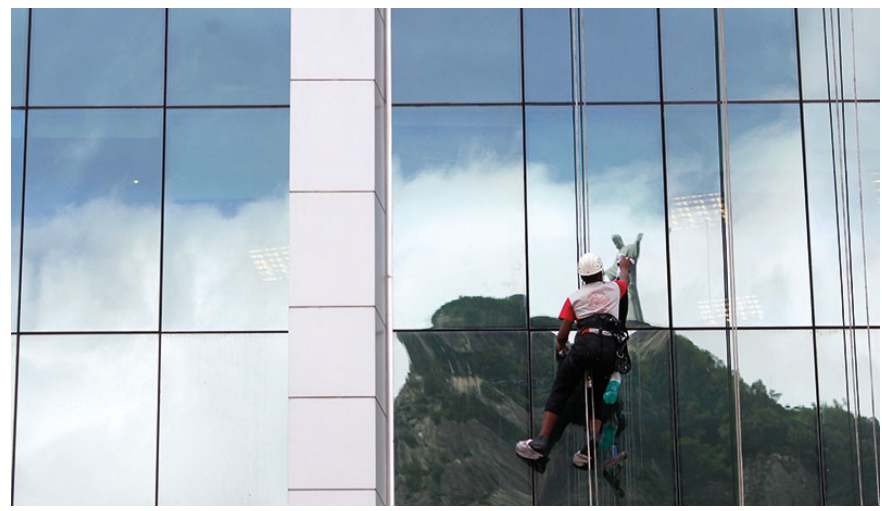

Fonte: http://photos.uol.com.br/materias/ver/96281. Foto: Ricardo Moraes

O contraste de tamanho entre a estátua do Cristo Redentor e o limpador de janelas da Figura 11 gera um contraste ainda mais interessante entre o real e a ficção, numa montagem 
natural em que o homem alcança o Cristo, limpando-o. O que se vê pode ser uma construção de contraste. A partir da presença do contraste predominantemente entre os discursos da comunicação publicitários e jornalísticos, "que na sua forma escrita são, para muitos falantes, os únicos objetos de leitura na sociedade actual" (COIMBRA, 2007, p. 1), acreditamos na pertinência de estudos sobre figuras de retórica e planejamento visual. Perceber o que e como se contrasta é também revelar posições argumentativas de um texto, seja visual ou sincrético ${ }^{6}$.

\section{Considerações Finais}

A partir de exemplo sobre a figura de retórica Quiasmo, inicialmente apresentado pela professora Tereza Virgínia Ribeiro Barbosa, em seminário na Universidade Federal de Minas Gerais, relacionamos a figura ao princípio do contraste, em que diferentes elementos se posicionam de forma oposta e planejados visualmente, a fim de chamar a atenção para seu conteúdo, conquistar e persuadir o público a, pelo menos, tomar conhecimento da mensagem, seja ela publicitária ou jornalística.

Em concordância com as explicações sobre quiasma, que afirmaram haver nessa figura de construção uma oposição entre partes de frases (RIBEIRO, s/d) e uma relação com as dicotomias e oposições conceituais (GONZÁLES, 1995 apud COIMBRA, 2007), percebemos na figura quiasma a presença do contraste entre as construções frasais. Essa percepção foi reforçada quando nos deparamos com exemplos célebres de quiasma, tais como "os últimos serão os primeiros, e os primeiros serão os últimos" (MATEUS, 20, 16) que vem contrastar, contrapondo os significados e as posições dos vocábulos.

Mesmo concluindo que o contraste no quiasma acontece principalmente pelo cruzamento de lugar (e não de significado), ao retomarmos Barbosa (2014), concluímos que ao posicionar dois elementos diferentes (semear X colher, chorar X cantar), a figura quiasma, exemplificada pela professora, não apresenta uma oposição dicotômica que separa os elementos de forma cartesiana. É um contraste de posição, em que as palavras/ideias se posicionam em lados separados, mas num arranjo orgânico, interdependentes, sem extremismos.

Tanto na figura de retórica quiasma quanto no princípio de design contraste, é a diferenciação contrastante que hierarquiza as informações da mensagem visual, levando o leitor/público a perceber o que é mais importante, pelo destaque proporcionado por elementos diferentes que, estando próximos, mesmo que de forma cruzada, chamam a atenção.

\footnotetext{
${ }^{6}$ Constituído de várias linguagens, verbal e não-verbal, segundo a semiótica francesa.
} 
Se é a forma discursiva contextualizada que define a função argumentativa e estilística da figura de retórica, entendemos que na relação entre a figura quiasma e o princípio contraste essas funções se interlaçam e se complementam. Isso porque a mensagem visual, enquanto estilo, argumenta, o que ocorre na hierarquia de posições dos seus elementos.

\section{Referências}

AUMONT, Jacques. A Imagem. 8 ed. Campinas, SP: Papirus, 2004.

ABRANTES, José Carlos. Breves Contributos para uma Ecologia da Imagem. Universidade de Coimbra. Comunicação apresentada no V Encontros Culturais Escola Secundária Nuno Alves Castelo Branco, 1999. Disponível em: http://www.bocc.ubi.pt/pag/abrantes-jc-ecologiaimagem.pdf. Acesso em: 26 maio 2014.

ARISTÓTELES. Arte Retórica e Arte Poética. Rio de Janeiro: Ediouro, 2005.

BARBOSA, Tereza Virgínia. A Retórica: de suas origens aos dias atuais. Belo Horizonte: FALE/UFMG, 2014. Notas de aula

BARTHES, Roland. A retórica da imagem. In: O Óbvio e o Obtuso: ensaios críticos III. Rio de Janeiro: Nova Fronteira, 1990.

BONHOMME, Marc. De l'argumentativité des figures de rhétorique. In: Argumentation et Analyse du Discours [En ligne], 2 | 2009. Disponível em http://aad.revues.org/495. Acesso em: 17 maio 2014.

CHARAUDEAU, Patrick e MAINGUENEAU, Dominique. Dicionário de Análise do Discurso. Coordenação da tradução Fabiana Komesu. São Paulo: Contexto, 2004.

CIBERDÚVIDAS DA LÍNGUA PORTUGUESA. Disponível em: http://www.ciberduvidas.pt/pergunta.php?id=4481. Acesso em: 27/05/2014. Acesso em: 17 maio 2014.

COIMBRA, Rosa Lídia. O quiasmo na publicidade escrita portuguesa. Uma abordagem cognitiva. In: M. Lobo e M. A. Coutinho (Orgs.) XXII Encontro Nacional da APL. Textos Seleccionados. Lisboa: APL, 2007, 251-260. Disponível em: http://www.apl.org.pt/docs/22textos-seleccionados/18-Coimbra.pdf. Acesso em: 18 maio 2014.

DÍAZ, Martha C. Chamorro. 2005. El humor gráfico desde una perspectiva retórica. In: Icono 14 Revista de Comunicación y nuevas tecnologias, v. 3, $\mathrm{n}^{\circ}$ 1, Madrid, 2005. Disponível em: http://www.icono14.net/ojs/index.php/icono14/article/view/441. Acesso em: 22 abr. 2014.

FERREIRA, Ivone et al. Em defesa de uma retórica da imagem. In: Rhêtorikê Revista Digital de Retórica. $\mathrm{n}^{\circ}$ 0, 2008, Universidade da Beira Interior, Covilhã, Portugal. Disponível em: http://www.rhetorike.ubi.pt/00/pdf/ferreira-prior-bogalheiro-

em_defesa_de_uma_retorica_da_imagem.pdf. Acesso em: 22 abr. 2014. 
GONZALES, Lucilene. Linguagem Publicitária: análise e produção. São Paulo: Arte \&Ciência, 2003. Disponível em: livros01.livrosgratis.com.br/cp020507.pdf. Acesso em: 04 jun. 2014.

HUBERT, Elizabete Enz. Relações Discursivas nas Sátiras a Religiosos atribuídas a Gregório de Matos Guerra (1633-1696). Figuras e estratégias argumentativas. 2011. Tese (Doutorado em Filologia e Língua Portuguesa) - Universidade de São Paulo, São Paulo, 2011. Disponível em: www.teses.usp.br/teses/disponiveis/8/8142/tde-16042012-121159. Acesso em: 22 abr. 2014.

JOLY, Martine. Introdução à Análise da Imagem. Trad. De Marina Appenzeller, 2. ed. São Paulo: Papirus, 1996.

KRIEG-PLANQUE, Alice. Por uma análise discursiva da comunicação: a comunicação como antecipação de práticas de retomada e de transformação dos enunciados. Tradução: Luciana Salazar Salgado. In: Revista Linguasagem, 16. ed. Universidade Federal de São Carlos, São Carlos/SP, 2011. 1-14. Disponível em:

http://www.letras.ufscar.br/linguasagem/edicao16/art_001.pdf. Acesso em 22 abr. 2014.

MUCCI DANIEL, Laene. Editoração Gráfica. Viçosa: DCM/UFV, 2014. Notas de aula.

PINHEIRO, Kelly Cristina Lourenço. A publicidade sob a ótica da hipérbole: o exagero como o argumento retórico. 2012. 155f. Dissertação (Mestrado) - USCS, São Caetano do Sul, 2012. Disponível em: http://repositorio.uscs.edu.br/handle/123456789/257 Acesso em: 22 abr. 2014.

PIRELMAN, Chaïm e OLBRECHETS-TYTECA, Lucie. Tratado da Argumentação. A nova retórica. Trad. de Maria Ermantina de Almeida Prado Galvão, São Paulo: Martins Fontes, 2005.

REBOUL, Olivier. Introdução à Retórica. São Paulo: Martins Fontes, 2004.

RIBEIRO, Guilherme. Recursos Estilísticos. Aveiro, Portugal: Escola secundária Dr. Jaime Magalhães Lima,s/d. Disponível em:

http://esjmlima.prof2000.pt/figuras_estilo/figurestil.htm\#Bm138. Acesso em 22 abr. 2014.

SANTARELLI, Christiane Paula Godinho e SOUZA, Sandra Maria Ribeiro. Análise da imagem publicitária: revisão de alguns modelos. In: XXIX Congresso Brasileiro de Ciências da Comunicação, Brasília/DF,2006. Disponível em:

http://www.intercom.org.br/papers/nacionais/2006/resumos/R1508-1.pdf. Acesso em: 18 maio 2014.

Quiasmo. In Infopédia [Em linha]. Porto: Porto Editora, 2003-2014. Disponível em: http://www.infopedia.pt/\$quiasmo. Acesso em: 13 maio 2014.

VERÍSSIMO, Jorge. A Publicidade da Benetton: Um discurso sobre o real. Coimbra, Portugal: Minerva Coimbra, 2001.

WILLIAMS, Robin. Design para quem não é Designer. Noções básicas de planejamento visual. São Paulo: Callis, 1995. 